\title{
Carta às Editoras sobre o artigo de Melo et al.
}

\author{
Letter to the Editors on the paper by Melo et al.
}

Carta a las Editoras sobre el artículo de Melo et al.

Lia Zumblick Machado 1

Chaiana Esmeraldino Mendes Marcon 1

doi: 10.1590/0102-311X00028721

Realizamos a leitura do estudo de Melo et al. 1, e gostaríamos de parabenizar os autores por esse excelente artigo e fazer algumas contribuições. O artigo teve como objetivo avaliar as reações adversas a medicamentos (RAMs) nos pacientes com COVID-19 e os fatores associados ao surgimento de reações graves. Nesse contexto, considero pertinente trazer à discussão a questão da automedicação. A automedicação é um hábito no Brasil, sendo comum em aproximadamente $77 \%$ dos brasileiros, segundo dados do Conselho Federal de Farmácia (CFF) de 2019. O pânico instalado pela pandemia do COVID-19 contribuiu negativamente para o aumento desse hábito 1 .

As redes sociais disponíveis por intermédio da Internet, no cenário da pandemia, são um importante canal de comunicação, contudo, mostrou-se também ser um veículo de compartilhamento de fake news. Há propagação em massa de informações contrárias às recomendações da Organização Mundial da Saúde (OMS). Dessa forma, a desinformação, bem como a negação da ciência, tem contribuído para que as pessoas se automediquem 2 .

De acordo com um levantamento realizado pela consultoria IQVIA (Instituto de Pesquisa e Pósgraduação para o Mercado Farmacêutico), houve um aumento de 180\% nas vendas de vitamina C. Fato ocorrido também com a hidroxicloroquina, que teve suas vendas aumentadas em cerca de $68 \%$ entre janeiro e março, depois de ser defendida como suposta cura para a COVID-19. É importante lembrar à população que mesmo medicamentos isentos de prescrição, como é o caso da vitamina $\mathrm{D}$, podem causar danos quando usados sem indicação e orientação profissional 1 .

A automedicação não coloca apenas a saúde individual em risco, como é o caso nas reações adversas. Há também prejuízo coletivo, visto que as pessoas que se automedicam podem ter a falsa sensação de segurança contra a infecção causada pelo novo coronavírus, tendendo a desrespeitar o isolamento social e as orientações da OMS. Além disso, o uso indiscriminado de antibiótico, como é o caso da azitromicina, contribui para o desenvolvimento da resistência bacteriana, que também gera um problema coletivo 3,4.

Em última análise, o aumento da automedicação é explicado pela insegurança e pânico trazidos pela situação de pandemia, aliado à desinformação e à negação da ciência. As consequências vão além do âmbito individual, contribuindo para o colapso do sistema de saúde como um todo 5. Portanto, a automedicação é um tema que merece atenção da comunidade científica, principalmente no que diz respeito ao combate a notícias falsas com informação.
1 Universidade do Sul de Santa Catarina, Tubarão, Brasil.

\section{Correspondência} L. Z. Machado Rua Recife 498, Tubarão, SC 88701420, Brasil. liazumblick@gmail.com 


\section{Colaboradores}

L. Z. Machado redigiu o texto. C. E. M. Marcon revisou o texto.

\section{Informações adicionais}

ORCID: Lia Zumblick Machado (0000-0002-00212607); Chaiana Esmeraldino Mendes Marcon (0000-0001-7031-437X).
1. Melo JRR, Duarte EC, Moraes MV, Fleck K, Silva ASN, Arrais PSD. Reações adversas a medicamentos em pacientes com COVID-19 no Brasil: análise das notificações espontâneas do sistema de farmacovigilância brasileiro. Cad Saúde Pública 2021; 37:e00245820.

2. Valécio M. COVID-19 aumenta a venda de ansiolíticos para insônia e vitaminas. https:// www.ictq.com.br/varejo-farmaceutico/1552covid-19-aumenta-venda-de-ansioliticos-me dicamentos-para-insonia-e-vitaminas (acessado em 02/Fev/2021).

3. Guimarães AS, Carvalho WRG. Desinformação, negacionismo e automedicação: a relação da população com as drogas "milagrosas" em meio à pandemia da COVID-19. InterAmerican Journal of Medicine and Health 2020; 3:e202003053.

4. Luccheta CR, Mastroianni PC. Rational use of chloroquine and hydroxychloroquine in times of COVID-19. Revista de Ciências Farmacêuticas Básica e Aplicada 2019; 40:e643.

5. Nasir M, Chowdhury ASMS, Zahan T. Selfmedication during COVID-19 outbreak: a cross sectional online survey in Dhaka city. Int J Basic Clin Pharmacol 2020; 9:1325-30. 